\title{
Decompressive Craniectomy in Patients with Malignant Middle Cerebral Artery Infarction: Prognostic Factors and Timing Dilemma
}

\author{
AYMAN M. ISMAIL, M.D.*; FATEN FAWZY MOHAMED, M.D.** and MONA M. AMER, M.D.*** \\ The Department of Neurosurgery, Faculty of Medicine*, The Department of Radiology, Faculty of Medicine ${ }^{* *}$ and \\ The Department of Neurology, Faculty of Medicine***, Zagazig University, Egypt
}

\begin{abstract}
Background: About 10 percent of ischemic strokes are defined as a malignant one due to associated massive brain edema which is severe enough to produce elevated intracranial pressure and brain herniation. Decompressive Craniectomy (DC) with duraplasty is a surgical technique that involves the creation of extra roomy space and incision of the tight dural covering the brain allowing swollen brain tissue to herniate outwards to reduce the Intracranial Pressure (ICP).
\end{abstract}

Aim of Study: This study aims to share the experience of performing decompressive craniectomy in the treatment of malignant Middle Cerebral Artery Infarction (MMCAI) $>48$ hours after stroke with an analysis of the results and prognostic factors.

Patients and Methods: From January 2016 to June 2018, we performed a decompressive craniectomy in eleven patients with massive middle cerebral artery infarction. Retrospectively we reviewed the clinical and radiological data, Glasgow coma scale at admission, pre and post-operatively. Serial Computed Tomography (CT) with measurement of midline shift pre and post-operatively. Patients were evaluated according to the following factors: Age, sex, the time between admission and surgery, the time between deterioration and surgery, the pre and post-operative Glasgow coma scale, pre and post-operative midline shift on CT scan, dominancy, and Glasgow outcome scale.

Results: Eleven patients (11) have been operated on by decompressive hemicraniectomy and duroplasty, there were no significant changes in outcome in relation to the admission GCS, GCS ( $p=0.2599)$ or in GCS ( $p=0.3713)$, but there was a significant correlation between the pre-operative GCS and outcome and decompressive craniectomy leads to highly significant relieve of the midline shift $(p<0.000)$. No significant correlation was detected between the time interval elapsed between admission and the time surgery and patient outcome $(p=0.3032)$, but there was also a significant correlation between the time interval between patient deterioration and time of decompressive craniectomy and patient outcome $(p=0.92161)$.

Conclusion: Very strict close observation of patients with Malignant Middle Cerebral Artery (MMCA) infarction in the

Correspondence to: Dr. Ayman M. Ismail, E-Mail: aymanmismael@gmail.com
Neuro ICU is highly recommended and surgery should be done as early as possible before the clinical deterioration of the brain herniation for better benefit. Decompressive craniectomy could be a life-saving procedure for large hemispheric infarction but postoperative morbidity and quality of life are the main challenges. Although early surgery is recommended by many studies but still DC even after 48 hours may be a life-saving procedure for some patients especially those operated on within a small time window once the clinical deterioration has happened but the post-operative morbidity and quality of life are the main challenges.

Key Words: Middle cerebral artery - Edema-Decompressive craniectomy.

\section{Introduction}

ABOUT ten percent (10\%) of ischemic strokes are defined as a malignant one due to associated massive brain edema which is severe enough to produce elevated intracranial pressure and brain herniation [1].

The Middle Cerebral Artery (MCA) is the most common vessel affected by CVA. More distal MCA occlusion tends to produce milder deficits due to more collaterals but the most proximal blockage leads to widespread effects that lead to cerebral edema, increased intracranial pressure, and disturbed conscious level that could be fatal [2]. The mmalignant middle artery infarction defined as an infarction involves more than $>50$ percent of MCA territory as defined by CT and/or MRI with an acute onset of corresponding clinical signs and symptoms [3]. Patients with malignant MCA infarction rapidly deteriorate within 24 days and are associated with high mortality reaching up to $80 \%$ percent without proper management [4]. Clinically, patients with malignant MCA infarction may present with hemiplegia, aphasia, neglect, forced gaze deviation, and visual field defect, the mortality 
is high due to herniation of the temporal lobe on the brain stem [5,6]. Radiological predictors for malignant edema after large MCA infarction include hyperdense MCA sign, hypodensity on brain CT involving more than $>50 \%$ percent of the MCA territory, midline shift of the septum pellucidum $>5 \mathrm{~mm}$, infarction of other vascular territories, and larger volume of infarction (> 140ml within 14 hours of stroke onset) on MRI as measured by diffusion-weighted imaging [7,8]. Clinical predictors of malignant infarction are young age, female gender, absence of the previous stoke, and systolic blood pressure $>180 \mathrm{mmHg}$ during the first 12 hours. Decompressive craniectomy and duraplasty is a surgical technique involving the creation of extra roomy space and incision of the tight dural covering the brain allowing the swollen brain tissue to herniate outwards to reduce the Intracranial Pressure (ICP) and cutting the vicious circle of extensive edema and further infarction [9]. The term decompressive craniectomy was first introduced by Kocher in 1901 and Harvey Cushing in 1905 and was first utilized specifically as a more extensive approach for massive cerebral infarction in 1956 [12,13]. Over the last decades, several reports have shown that Decompressive Craniectomy (DC) can't only reduce mortality but can also result in a good functional outcome especially in younger patients [3]. Although DC looks like a simple procedure but really it is not without complication which includes hemorrhagic infarction, necrosis, hematoma ,edema at the site of craniectomy, infection, seizures subdural hygroma, and hydrocephalus. Sinking Skin Flap Syndrome (SSFS) is another delayed known complication of craniectomy can occur when atmospheric pressure exceeds intracranial pressure [15]. Therefore, the aim of this work is to share the authors' experience with Decompressive Craniectomy (DC) in malignant MCA infarction with a special focus on patients operated outside 48 hours after onset of stroke.

\section{Patients and Methods}

This a retrospective study of eleven 11 patients with malignant middle cerebral artery infarction operated at Neurosurgical Department, Zagazig University Hospital by the first author between January 2016 and June 2018. All cases operated after 48 hours of stroke onset. The cases initially admitted to in the stroke unit under the care of the Neurology Department, neurosurgical consultation would have proceeded and a large decompressive craniectomy has been performed in the event of neurological deterioration and radiological evidence of severe cerebral edema secondary to the infarction with the following criteria: (1) Unilateral MCA infarction with hypodensity $>50 \%$ of MCA territory, (2) Midline shift more than 5mm, (3) Large volume of infarction $>140 \mathrm{ml}$ within 14 hours of stroke onset on brain DWMRI.

\section{Exclusion criteria:}

1- MCA infarction with hypodensity $<50 \%$ of MCA territory.

2- MCA infarction with midline $<5 \mathrm{~mm}$.

3- MCA infarction with other vascular territories.

4- Bilateral infarctions.

5- Patients with MCA infarction who received rtpA.

6- Patients with a medical contraindication to surgery.

The condition of the patients and the surgical approach discussed in detail with the relatives and written consent has done, stated that the condition is very critical and an approach is a lifesaving approach. The procedure performed in the study was in accordance with the ethical standards of the institutional research committee and with the 1964 Helsinki declaration and its later amendments.

Pre-operatively patients had routine preoperative laboratory investigation, serial CT brain, MRI, and CT angiography done in some cases, the following data such as (age, sex affected hemisphere, admission GCS, pre-operative GCS, time from admission to surgery, time from deterioration to surgery, measurement of pre and post-operative midline shift, Glasgow outcome score) were collected, tabulated, and analyzed.

Surgical procedure: Figs. (6-9) a large frontotempro-parietal craniectomy (diameter $>12 \mathrm{~cm}$ ) was performed to include the frontal, parietal, and temporal lobes, a large craniectomy is essential to avoid both incomplete releases of the pressure and further injury to the brain if it is forced against the edges of the bony skull defect. The dura was incised as a curvilinear dural flap in 6 cases and in 5 cases a stellate-shaped durotomy centered on the flap has done. Duraplasty performed using pericrania and temporalis fascia which placed overlying the dural defect. The infarcted brain tissue was not excised. Bone flap removed in all cases and implanted in the abdominal wall to be ready for cranioplasty except one case bone flap has been repositioned floating at the same sitting by the end of surgery because the patient was very critical by 
the end of the operation. Cranioplasty was done in 3-6 months after discharge in most cases.

Post-operatively: All patients were sent to the neurosurgical ICU for close monitoring and management. The patients were mechanically ventilated to maintain mild hyperventilation and received medical management such as intravenous mannitol, steroids, diuretics, and sedative agents.

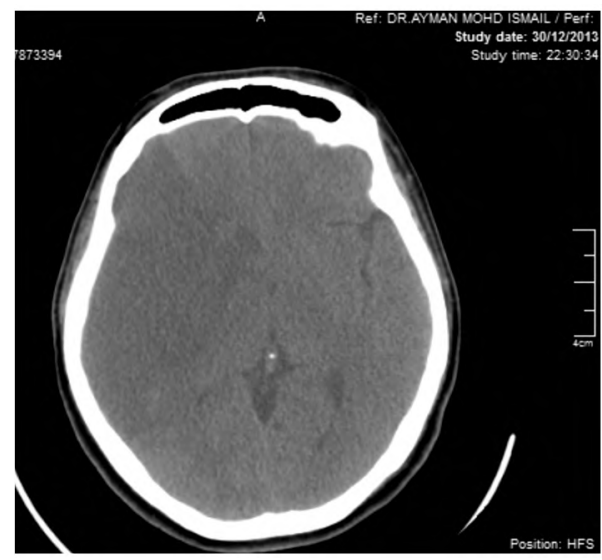

Fig. (1): Initial CT, showed minimal right MCA distribution hypodensity few hours after the stroke.

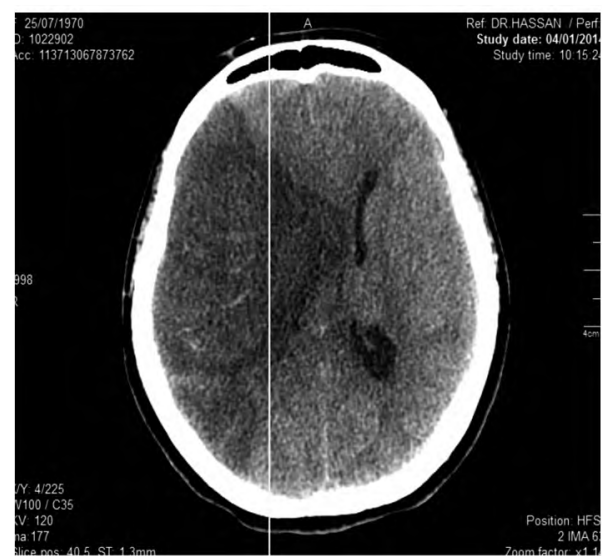

Fig. (3): CT brain 5 days post stroke (pre-operative CT brain) showed the infarction and swelling the midline shift is $11.2 \mathrm{~mm}$ and preoperative GCS 7 .

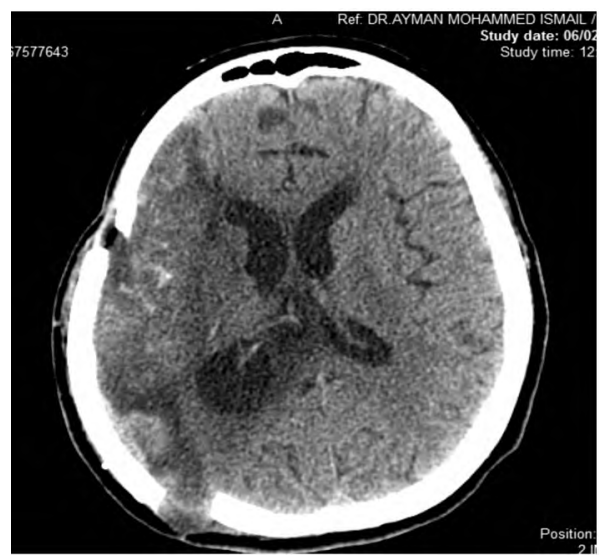

Outcome: Using the Glasgow Outcome Scale (GOS), patients with GOS of 1 to 3 were included in the poor outcome group and patients with a GOS of 4 to 5 were included in the good outcome group. Patients' outcome was evaluated one week, one, three, and six months post-operatively using hospital records, discharge summaries, outpatient notes, and telephonic interview.



Fig. (2): CT brain 2 days post stroke showed marked hypodensity.

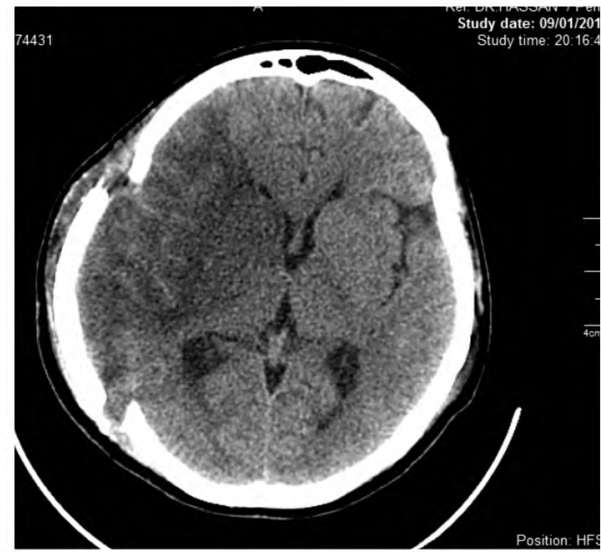

Fig. (4): Post-operative CT brain revealed improving midline shift and swelling on early post-operative CT brain (5 days post-operative).

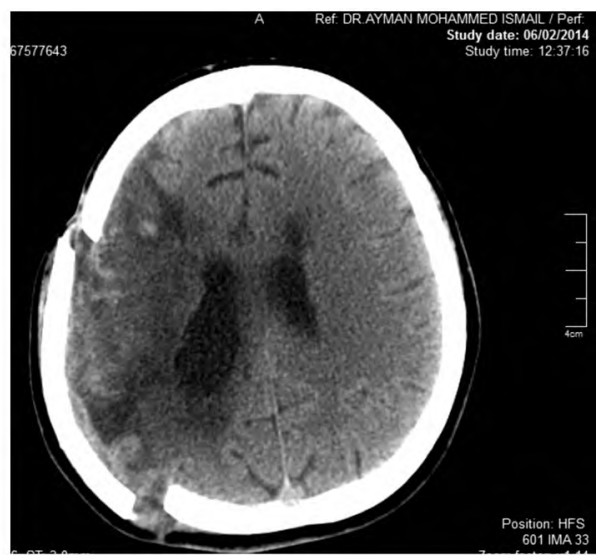

Fig. (5): Post-operative CT brain (one month). No midline shift ipsilateral compensatory right lateral ventricular dilation. Floating bone flap. 


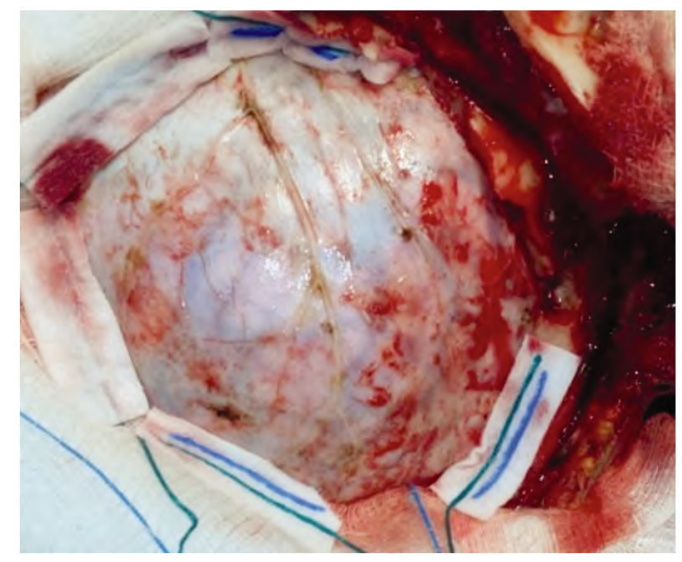

Fig. (6): Intra-operative photo revealed the extent of craniectomy, how much the dura is tense?

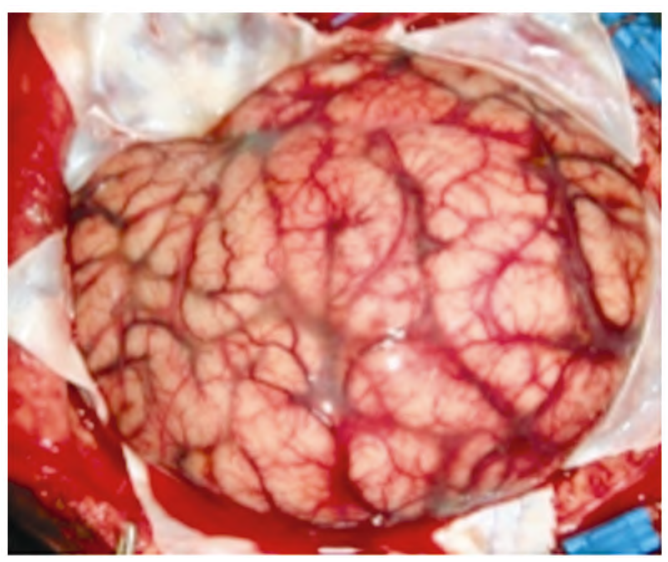

Fig. (8): The dural opening in a stellate fashion.

Statistical analysis: Results were compared statistically using the SPSS program version 17 (Chicago, IL, USA). $t$-test was used to compare different means while the Pearson Correlation Coefficient and R2; the coefficient of determination was used to find the correlation between different readings. When $p$-value is $<0.05$, it is considered statistically significant.

\section{Results}

In the current retrospective study, eleven patients were included (five males, six females) with a mean age of $57.81 \pm 5.96$ (47-67) years. Non dominant hemisphere affected in 6 patients $(54.5 \%)$ and dominant one in 5 patients $(45.5 \%)$. The mean Glasgow Coma Score (GCS) at admission was $12 \pm$ 2.7386 while the post-operative GCS after one week was $11.5 \pm 3.144$ with no significance ( $p$-value 0.3713 NS). The mean pre-operative Glasgow Coma Score (GCS) $8.5 \pm 1.876$ while the postoperative GCS after one week was $11.5 \pm 3.144$ with significant relation ( $p$-value $0.0133 \mathrm{~S}$ ).

The mean midline shift pre-operatively was $8.27 \pm 1.135 \mathrm{~mm}$ while one week post-operatively,

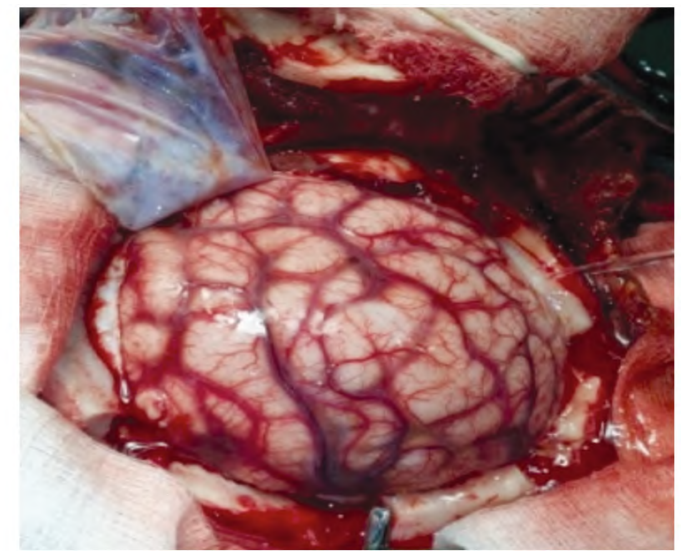

Fig. (7): Intra-operative photo showed the curvilinear opening of the dura, dura reflected anteriorly and inferiorly.

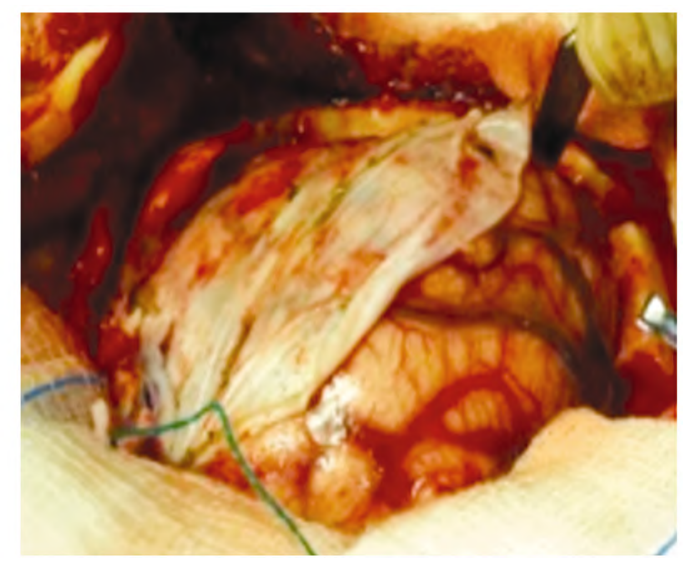

Fig. (9): Duroplasty and closure.

it was $4.36 \pm 0.979 \mathrm{~mm}(p<0.000)$ with high significant relation. The patients' outcome at 6 months was the same as that at 1 and 3 months except for only one case of severe disability group improved to be in the moderate disability group.

The mean time duration between admission and surgery was $3.90 \pm 0.83$ (3-5) days. The mean time elapsed between the deterioration of the conscious level and surgery was $5 \pm 2.32$ (2-10) hours. The patient's outcome was as follows; 3 cases died, 3 cases had a severe disability, 2 cases had moderate disability, 3 cases had a minimal neurological defect.

No significant correlation was detected about time (between admission time and time of surgery) and outcome ( $p=0.303269)$ but there was a highly significant correlation between time (between deterioration till the start of DC) outcome ( $p=$ 0.000299 ) (Table 2). So less duration was significantly associated with a better outcome. There is also a significant correlation between pre-operative GCS and patients outcome ( $p=0.00186)$ so the less pre-operative GCS, the worse outcome of the patients. 
Table (1): Patient's outcome after decompressive craniectomy.

\begin{tabular}{lllcl}
\hline Outcome & Time of evaluation & Mean \pm SD & $t$-test & $p$-value \\
\hline GCS & On admission & $12 \pm 2.7386$ & 2.7177 & 0.3713 NS \\
& One week post & $11.5 \pm 3.144$ & & \\
GCS & Pre-operative & $8.5 \pm 1.876$ & 0.9145 & $0.0133 \mathrm{~S}$ \\
& One week post & $11.5 \pm 3.144$ & & \\
& Pre-operative & $8.27 \pm 1.135$ & 8.6493 & $<0.0001 \mathrm{HS}$ \\
\hline
\end{tabular}

GCS : Glasgow Coma Scale. NS: Non-Significant.

SD : Slandered Deviation. HS: Highly Significant.

Table (2): Correlation between patient's outcome and time interval.

\begin{tabular}{|c|c|c|c|}
\hline & $r$-test & $p$-value & Significant \\
\hline Time elapsed between admission and operation & -0.3425 & 0.303269 & NS \\
\hline Time elapsed between deterioration and operation & 0.8845 & 0.000299 & HS \\
\hline Pre-operative GCS & -0.823 & 0.00186 & $\mathrm{~S}$ \\
\hline
\end{tabular}

\section{Discussion}

With the best conservative treatment, the mortality rates of malignant MCA infarction reaching up to $80 \%$ [4]. The term decompressive craniectomy was first introduced by Harvey Cushing in 1905 and was first utilized specifically as a more aggressive treatment for massive cerebral infarction in $1956[\mathbf{1 0 , 1 2}]$. Patient age may be an important variable when considering treatment with hemicraniectomy, younger patients may have a better functional outcome and decreased mortality than older patients as demonstrated by DECIMAL, HAMLET, DESTINY trials which stated also patients $>60$ years of age do not achieve good neurologic outcome regardless of the treatment $[3,16]$ In our study, the mean age in good and poor outcome groups was (53.66 \pm 4.54 (47-58), 62.80 \pm 2.48 (61-67) years respectively, age in our study was significant concerning the outcome. The relationship of midline shift in presurgical CT scan and prognosis has been discussed in many series which found no relationship between midline shift and outcome [17], but others reported that midline shift ${ }^{3}$ $11 \mathrm{~mm}$ is associated with poor outcome [18]. In our study, midline shift was significant, the mean midline shift was $7.71 \pm 1.11(6-9) \mathrm{mm}$ in the good outcome group of patients and it was $9.2 \pm 0.447$ (9-10) $\mathrm{mm}$ in the poor outcome group of patients. It was often thought that DC must be restricted only to patients with non-dominant hemispherical strokes because the outcome would be better and the speech function is unaffected [19]. In contrast, some reports stated that no significant difference in outcome between patients of dominant and non- dominant strokes $[\mathbf{2 0 , 2 1 ]}$. In our study, we found no significance in the outcome between $\mathrm{Lt}$ and $\mathrm{Rt}$ strokes. Also, we have found improvement in speech in one case, and this consistent with some studies that reported that decompressive craniectomy increases leptomeningeal collaterals, brain perfusion, decreases the infarction size, and improves the prognosis $[\mathbf{2 2 , 2 3}$. Timing of surgery is one of the most important controversial prognostic factors, most of the reports which discussed the time issue of DC reported that early or ultra-early intervention is the recommended option, some investigators found that early surgery is a good prognostic factor and Decompressive Craniectomy (DC) within 48 hours is more likely to be beneficial than later hemicraniectomy with no benefit noticed in patients operated on after 4 days of symptoms $[16,19,25]$. On the other side, some studies reported no significant correlation between time from admission to surgery and outcome $[\mathbf{1 4 , 2 0 , 2 1 ]}$. In our study, although all cases were operated on after 48 hours, there is still a good number of patients benefit from late surgery provided that the time window between the starting of the deterioration and the intervention is as short as possible. One of the most important prognostic factors we noticed is the time from starting deterioration to the time of intervention not the time interval from admission to surgery, cases which were done within a small time window gave favorable outcomes. Due to most of our patients referred late from neurologists after deterioration started already, usually, we don't have the choice to do DC on an early and ultraearly basis, only we have the option to do it as early as the patient referred. Forty-eight hours or 
even ninety-six hours post-stroke in cases of MMCAI is not a contraindication to DC, but still, early or ultra-early surgery is advisable.

As demonstrated by randomized controlled trials DECIMAL, HAMLET trial and DESTINY I, II, the main benefit of hemicraniectomy for both younger and older patients have increased survival but the main problem we noticed also is not the survival or absolute mortality but the quality of life (most patients who survive are left with moderate to seven disability) $[\mathbf{3 , 2 4 , 2 6 ]}$, so we recommend a thorough discussion between the neurosurgeon and the relatives should be done about the nature of the approach, functional outcome and the expected delayed complication.

\section{Conclusion:}

Decompressive hemicraniectomy is considering a life-saving procedure for large hemispheric infarction. Pre-operative GCS, pre-operative midline shift in CT brain, the time interval between the deterioration and the surgery was considered important prognostic factors. Although early surgery is recommended by many but still DC even after 48 hours may be a life-saving procedure for some patients especially those operated on within a small time window once the clinical deterioration has happened.

\section{Recommendations:}

The surgical approach should be discussed in detail with the relatives to clarify that the patient may survive with a severe disability. Attention to clinical and radiological predictors of the malignant scenario of the stroke is very essential to operate early as a prophylactic procedure not to wait after the deterioration has happened Very strict close observation of patients with MMCA infarction in the Neuro ICU to be ready for intervention as early as possible once deterioration of conscious level decline. Number of the patients in this study is limited, so a large numbered randomized controlled study is needed.

\section{Compliance with ethical standards:}

Funding: No funding received.

Conflict of interest: The authors declare no conflict of interest.

Ethical approval: Approval from the Zagazig University review board (IRB) was taken and all procedures performed in studies were in accordance with the ethical standards of the institutional research committee and with the 1964 Helsinki declaration and its later amendments.

\section{References}

1- HACKE W., SCHWAB S., HORN M., et al.: 'Malignant' middle cerebral artery territory infarction: Clinical course and prognostic signs. Arch. Neurol., 53: 309, 1996.

2- KRIEGER D.W., DEMCHUK A.M., KASNER S.E., JAUSSM and HANSTON L.: Early clinical and radiological predictors of fatal brain swelling in ischemic stroke. Stroke, 30 (2): 287-92, 1999.

3- VAHEDI K., HOFMEIJER J., JUETTLER E., et al.: Early decompressive surgery in malignant infarction of the middle cerebral artery: A pooled analysis of three randomised controlled trials. Lancet Neurol., 6: 215, 2007.

4- WIJDICKS E.F. and DIRINGER M.N.: Middle cerebral artery territory infarction and early brain swelling: Progression and effect of age on outcome. Mayo Clin. Proc., 73: 829-36, 1998.

5- WIJDICKS E.F., SHETH K.N., CARTER B.S., et al. Recommendations for the management of cerebral and cerebellar infarction with swelling; a statement for healthcare professionals from the American Heart Association/American Stroke Association. Stroke, 45: 1222, 2014.

6- OPPENHEIM C., SAMSON Y., MANAI R., et al.: Prediction of malignant middle cerebral artery infarction by diffusion-weighted imaging. Stroke, 31: 2175, 2000.

7- BARBER P.A., DEMUHUK A.M., ZHANG J., et al.: Computed tomographic parameters predicting fatal outcome in large middle cerebral artery infarction. Cerebrovasc. Dis., 16: 230, 2003.

8- WIJMAN C.A.: Editorial comment-Can we predict massive space-occupying edema in large hemispheric infarctions? Stroke, 34: 1899, 2003.

9- FRANK J.I., SCHUMM L.P., WROBLEWSKI K., et al.: Hemicraniectomy and durotomy upon deterioration from infarction-related swelling trial: Randomized pilot clinical trial. Stroke, 45: 781, 2014.

10- CUSHING H.: The establishment of cerebral hernia as a decompressive measure for inaccessible brain tumors; with the description of intermuscualr methods of making the bone defect in temporal and occipital regions. Surg. Gynecol. Obstet., 1: 297, 1905.

11-KIM S.C., LEE J.K., KIM J. S., KIM T. S., JUNG S., KIM J.H., et al.: Clinical analysis of decompressivecraniectomy for acute massive cerebral infarction. J. Korean Neurosurg. Soc., 30: 278-83, 2001.

12-BALANI C. and ALLIEZ B.: Decompressive craniectomyfrom option to standard-Part II. Rom. Neurosurg., 17: 7380, 2010.

13- THOMALLA G., HARTMANN F., JUETTLER E., et al.: Prediction of malignant middle cerebral artery infarction by magnetic resonance imaging within 6 hours of symptom onset. A prospective multicenter observational stud. Ann. Neurol., 68: 435, 2010.

14- CHO T.K., CHEONG J.H., KIM J.H., BAK K.H., KIM C.H. and KIM J.M.: Efficacy of the decompressive craniectomy for acute cerebral infarction: Timing of surgical intervention and clinical prognostic factors. J. Korean Neurosurg. Soc., 40: 11-5, 2006.

15- AKINS P.T. and GUPPY K.H.: Sinking skin flaps, paradoxical herniation, and external bran tamponade: A review 
of decompressive craniectomy management. Neurocrit. Care, 9: 269, 2008.

16- CRUZ-FLORES S., BERGE E. and WHITTLE I.R.: Surgical decompression for cerebral oedema in acute ischaeic stroke. Cochrane Database Syst. Rev., 1: CD003435, 2012

17- RABINSTEIN A.A., MUELLER-KRONAST N., MARAMATTOM B.V., ZAZULIA A.R., BAMLET W.R., DIRINGER M.N., et al.: Factors predicting prognosis after decompressive hemicraniectomy for hemispheric infarction. Neurology, 67: 891-3, 2006.

18- HUH J.S., SHIN H.S., SHIN J.J., KIM T.H., HWANG Y.S. and PARK S.K.: Surgical management of massive cerebral infarction. J. Korean Neurosurg. Soc., 42: 3316, 2007.

19- CARTER B.S., OGILVY C.S., CANDIA C.J., et al.: Oneyear outcome after decompressive surgery for massive nondominant hemispheric infarction. Neurosurgery, 40 1168-76, 1997.

20- GUPTA R., CONNOLLY E.S., MAYER S. and ELKIND M.S.: Hemicraniectomy for massive middle cerebral artery territory infarction: A systematic review. Stroke, 35: 539 , 2004.
21- HARSCHER S., REICHART R., TERBORG C., HAGEMANN G., KALFF R. and WITTE O.W.: Outcome after decompressive craniectomy in patients with severe ischemic stroke. Acta Neurochir. (Wien), 148 (1): 31-7, 2006.

22- SCHWAB S., STEINER T., ASCHOFF A., SCHWARZ S., STEINER H.H., JANSEN O., et al.: Early hemicraniectomy in patients with complete middle cerebral artery infarction. Stroke, 29 (9): 1888-93, 1998.

23- FORSTING M., REITH W., SCHABITZ W.R., et al. Decompressive craniectomy for cerebral infarction. An experimental study in rats. Stroke, 26: 259, 1995.

24- JÜTTLER E., UNTERBERG A., WOITZIK J., et al.: Hemicraniectomy in older patients with extensive middlecerebral-artery stroke. N. Engl. J. Med., 370: 10911, 2014.

25- HOFMEIJER J., KAPPELLE L.J., ALGRA A., et al.: Surgical decompression for space-occupying cerebral infarction (the Hemicraniectomy After Middle Cerebral Artery infarction with Life-threatening Edema Trial [HAMLET]): A multicentre, open. Randomised trial. Lancet Neurol., 8: 326, 2009.

26- JÜOTTIER E., SCHWAB S., SCHMIEDEK P., et al.: Decompressive Surgery for the Treatment of Malignant infarction of the Middle Cerebral Artery (DESTINY): A randomized, controlled trial. Stroke, 38: 2518, 2007.

\section{إستئصال القحف فى مرضى جلطات الشريان الدماغى الآوسط الخبيثة

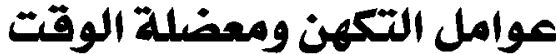

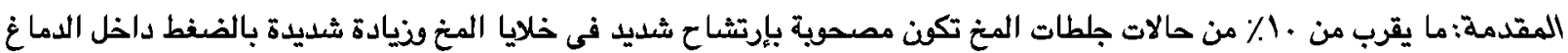

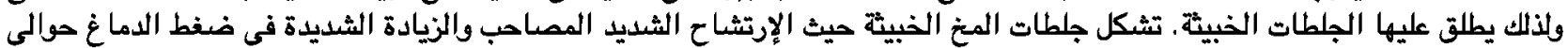

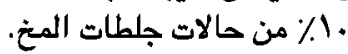

تعد عمليات إستئصال جزء كبير من القحف (عظام الجمجمة) وإعادة فتح الآم الجافية ورتقها إجراء جراحى لخلق فراغ إضافى يستوعب

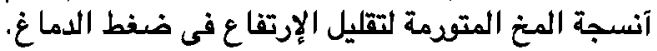

الهدف: الهدف من هذه الدراسة هي مشاركة الخبرة في إستخدام الإجراء الجراحى بإستئصال جزئ كبير من عظام القحف في حالات

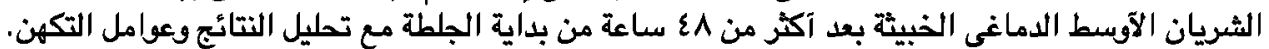

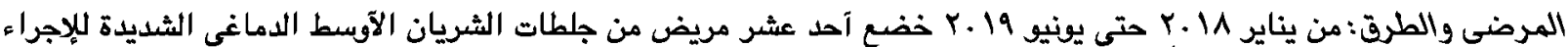

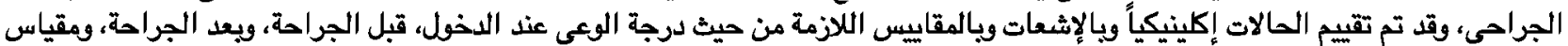

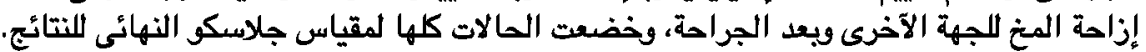

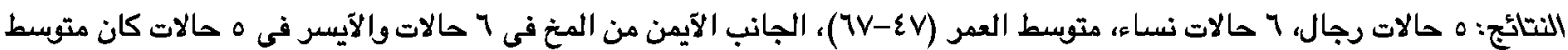

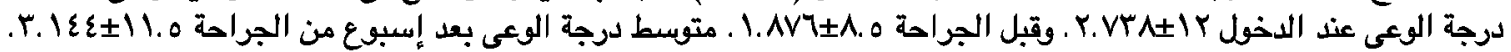

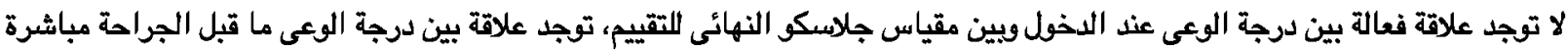

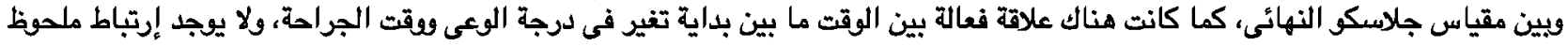
بين الوقت الزمنى الذى مر من وقت الدخول حانى النى الجراحة والنتيجة النهائية.

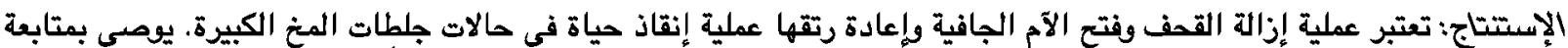

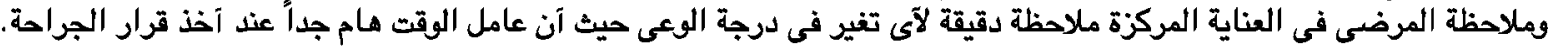

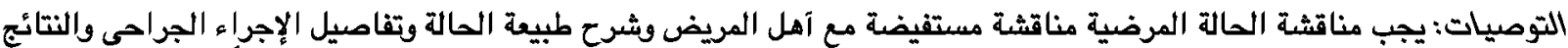

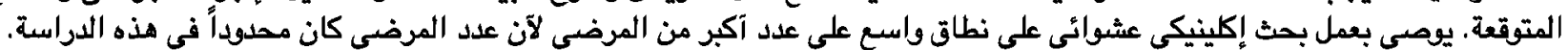

